\title{
Adipose Tissue-Derived Stem Cells in Regenerative Medicine
}

\author{
Laura Frese $^{a}$ Petra E. Dijkman ${ }^{a}$ Simon P. Hoerstrup ${ }^{a, b, c}$ \\ a Institute for Regenerative Medicine (IREM), University of Zurich, Zurich, Switzerland; \\ ${ }^{b}$ Department of Biomedical Engineering, Eindhoven University of Technology, Eindhoven, The Netherlands; \\ ${ }^{c}$ Wyss Translational Center Zurich, University of Zurich and ETH Zurich, Zurich, Switzerland
}

\section{Keywords}

Regenerative medicine - Adipose tissue-derived stem cells · Mesenchymal stem cells · Therapeutic application . Cell therapy · Tissue engineering

\section{Summary}

In regenerative medicine, adult stem cells are the most promising cell types for cell-based therapies. As a new source for multipotent stem cells, human adipose tissue has been introduced. These so called adipose tissue-derived stem cells (ADSCs) are considered to be ideal for application in regenerative therapies. Their main advantage over mesenchymal stem cells derived from other sources, e.g. from bone marrow, is that they can be easily and repeatable harvested using minimally invasive techniques with low morbidity. ADSCs are multipotent and can differentiate into various cell types of the trigerm lineages, including e.g. osteocytes, adipocytes, neural cells, vascular endothelial cells, cardiomyocytes, pancreatic -cells, and hepatocytes. Interestingly, ADSCs are characterized by immunosuppressive properties and low immunogenicity. Their secretion of trophic factors enforces the therapeutic and regenerative outcome in a wide range of applications. Taken together, these particular attributes of ADSCs make them highly relevant for clinical applications. Consequently, the therapeutic potential of ADSCs is enormous. Therefore, this review will provide a brief overview of the possible therapeutic applications of ADSCs with regard to their differentiation potential into the tri-germ lineages. Moreover, the relevant advancements made in the field, regulatory aspects as well as other challenges and obstacles will be highlighted.

(c) 2016 S. Karger GmbH, Freiburg

\section{Introduction}

Regenerative medicine holds great promise to repair damaged tissues and organs and restore functionality by stimulating the body's own regenerative capacity. The interdisciplinary field comprises several techniques and specialties, such as tissue engineering, medicine and molecular biology, to replace, engineer, or regenerate cells, tissues, or organs with the objective of restoration or establishing of the normal function.

In this regard various cell types have been investigated for their suitability in regenerative medicine, including adult mesenchymal stem cells (MSCs). The observed multipotency of MSCs, namely their ability to differentiate into cells of mesenchymal origin such as osteoblasts, adipocytes, myocytes and chondrocytes, sparked interest to investigate their potential for future cell-based therapies. In contrast to embryonic stem cells, the immune compatible stem cells derived from differentiated tissues are not subjected to ethical challenges [1]. Due to their wide availability MSCs represent an interesting cell source for regenerative medicine and are commonly isolated from the bone marrow [2, 3]. However, bone marrow-derived MSCs are suboptimal for clinical use due to the required highly invasive aspiration procedure and the decline in both their proliferation and differentiation potential with increasing senescence [4]. In search for an alternative stem cell source at the beginning of the 21st century, Zuk et al. [5] introduced a multipotent, undifferentiated, self-renewing progenitor cell population isolated from adipose tissue that is morphologically and phenotypically similar to the MSCs. These so-called adipose tissue-derived stem cells (ADSCs) as suggested by the Internal Fat Applied Technology Society display a capacity of differentiation similar to MSCs and show the expression of the specific stem cell markers in vivo [6]. Importantly, the ease of repeated accessibility to subcutaneous adipose tissue by a minimally invasive method, the simple isolation procedure, and a stem cell quality and proliferation capacity that

\section{KARGER \\ Fax +497614520714

\section{() 2016 S. Karger GmbH, Freiburg}

$1660-3796 / 16 / 0434-0268 \$ 39.50 / 0$
Prof. Dr. Simon P. Hoerstrup 
does not decline with the age of the patient outline the ADSCs' superiority as alternative clinical cell source and provide a clear advantage over bone marrow-derived MSCs $[7,8]$.

\section{Isolation and Characterization}

Subcutaneous adipose tissue consists predominantly of mature adipocytes and a heterogeneous stromal vascular fraction (SVF), which includes fibroblasts, endothelial cells, pre-adipocytes, vascular smooth muscle cells, lymphocytes, monocytes, and ADSCs [9]. The most widely utilized method to isolate ADSCs from fat tissue relies on a collagenase digestion, followed by centrifugal density gradient separation [10]. In vitro, ADSCs display a spindle-shaped morphology and lack the intracellular lipid droplets as seen in adipocytes. Isolated ADSCs are typically expanded in monolayer cultures on standard tissue dishes with a basal medium containing $10 \%$ fetal bovine serum [11]. However, in terms of the clinical translation the in vitro expansion of ADSCs has to be compliant with the good manufacturing practice (GMP) guidelines. In this context xenogeneic components for the cultivation of cells have to be avoided. A promising substitute has recently been found in human platelet lysate (HPL) [12], which is superior in terms of proliferation speed and allogenicity.

Similar to MSCs isolated from bone marrow, ADSCs show the stem cell-specific combination of surface markers, such as CD90, CD105, CD73, CD44and CD166, and lack the expression of the hematopoietic markers CD45 and CD34 [13].

According to current literature, the anatomical site of the adipose tissue does not affect the total number of viable cells that can be obtained from the subcutaneous fatty tissue [14, 15]. Comparative studies with ADSCs and bone marrow-derived MSC described minor differences regarding their differentiation potential and their immunomodulatory activity $[16,17]$. Thus, bone marrowderived MSCs had a slightly better osteogenic capacity, but ADSCs show a more effective collagen production. However ADSCs seem to be genetically and morphologically more stable in long-term cultures, with lower senescence and higher proliferation capacities [18]. Additionally, compared to bone marrow-derived MSCs, ADSCs show no statistically significant correlation between stem cell quality, proliferation capacity and the patient's age [8].

\section{Functional Roles of Adipose Tissue-Derived Stem Cells in Regenerative Medicine}

The beneficial effects of stem cells and therewith the paradigm of tissue regeneration may not be restricted to cellular restoration but may also be related to the transient paracrine actions of the cells [19]. In 2010 Roh et al. [20] reported that human-derived MSCs seeded on polymer scaffolds were no longer detectable within a few days after implantation in an immune deficient mouse recipient. Instead, the scaffolds became initially repopulated by murine monocytes and subsequently by smooth muscle and en- dothelial cells. The authors were the first to hypothesize that the pre-seeded and implanted MSCs have secreted significant amounts of monocyte chemoattractant protein-1 and therewith increased early monocyte recruitment in the recipient. These findings suggest that the tissue regeneration occurs via an inflammatory process rather than via cell restoration alone [20]. However, the biological role and regulatory mechanisms involved in this secretioninduced inflammatory phenomena still remain largely unknown.

\section{Therapeutic Applications of Adipose Tissue-Derived Stem Cells}

Stem cells, including ADSCs, have emerged as a key element of regenerative medicine therapies due to their ability to differentiate into a variety of different cell lineages. Moreover, their capacity of paracrine secretion of a broad selection of cytokines, chemokines, and growth factors make them highly clinically attractive. More specific, of particular interest are the anti-apoptotic, anti-inflammatory, proangiogenic, immunomodulatory, and anti-scarring effects that have been demonstrated for ADSCs [21], which make these cells promising candidates for cellular therapy in regenerative medicine.

To date, approximately 130 active clinical trials investigating the potential of ADSCs are listed on the US National Institutes of Health Website [22]. These clinical trials span a broad range of applications, such as soft tissue regeneration, skeletal tissue repair, ischemic injuries, myocardial infarction and immune disorders (including lupus, arthritis, Crohn's disease, multiple sclerosis, diabetes mellitus, and graft-versus-host disease). Other therapeutic targets that are being explored in clinical trials include intervertebral disc degeneration and pulmonary disease - to name just a few. As the therapeutic potential of the ADSCs is enormous, this review will concentrate on the most reported therapeutic applications of ADSCs with regard to their differentiation potential into the different lineages.

\section{Mesodermal Potential of Adipose Tissue-Derived Stem Cells}

Due to their origin, the earliest application of ADSCs in regenerative medicine was obviously for mesodermal regeneration, focusing on their potential for osteogenic, adipogenic, chondrogenic, and eventually also their cardiovascular application.

\section{Bone Regeneration}

Numerous studies have investigated the regenerative effect of transplanted ADSCs from rodents, rabbits, and humans on bone regeneration in a variety of defect systems [23, 24]. For instance, a painful disorder affecting the hip due to the avascular necrosis of the femoral head often leads in its final stage to osteoarthritis and 
the need for total hip replacement. In small animal studies, autologous ADSCs were directly injected into the femoral head. Two months after surgery, the ADSCs enhanced the osteogenesis and the microstructure of vascular deprivation-induced osteonecrotic tissue [25]. These beneficial effects of ADSCs were also reported in a case study where a combination of autologous ADSCs and spongy cells from the iliac crest were used to reconstruct the calvarial defects of a young girl after severe head injury. While a chronic infection after reconstructive surgery resulted in an unstable cranium with obvious bone defects, remarkably enough, 3 months after cell injection new bone formation and nearly complete calvarial continuity was observed [26].

\section{Fat Reconstruction}

The initial indication for fat transplantation was the correction of facial defects as well as breast reconstruction after mastectomy. As breast cancer remains the most common type of cancer in women, new techniques for postsurgical breast reconstruction constantly develop. Such new procedures to improve autologous fat grafting rely on the enrichment with autologous SVF, plateletderived growth factors, hormones and/or insulin [27, 28]. The reported improvement of fat graft viability with these techniques likely depends on the presence of ADSCs in the SVF. It is also known that in the process of adipose tissue repair after injury fibroblast growth factor-2 (FGF-2), among other injury-associated growth factors, strongly promotes ADSC proliferation and hepatocyte growth factor (HGF) secretion through a c-Jun N-terminal kinase (JNK) signaling pathway [29].

Although breast reconstruction has been the prominent clinical target for ADSC therapies, currently a wide range of applications exist in plastic and reconstructive surgery. More specific, the secretive properties of ADSCs to produce cytokines, chemokines, and growth factors may contribute to an effective and innovative antiscarring therapy. After injury, often hypertrophic scars occur due to abnormal extracellular matrix (collagen) deposition and remodeling or inflammation. Although nowadays a variety of therapies are available for the treatment of hypertrophic scars (e.g. excision, laser, IFN injection, etc.), none of these treatments has been confirmed to be effective in fully avoiding excessive scar tissue formation or regeneration of healthy dermal tissue [30]. The feasibility of ADSCs to attenuate the formation of hypertrophic scars through secreting anti-fibrosis cytokines and decreasing the $\alpha$-SMA and collagen type I gene expression was demonstrated in a rabbit ear hypertrophic scar model by locally intralesional injection of ADSCs [31].

\section{Cartilage and Intervertebral Disc Regeneration}

In the light of the aging population, the skeletal tissue is more and more affected. Consequently, today musculoskeletal disorders represent a major cause of disability and morbidity globally and result in enormous costs for health and social care systems. Chronic and inflammatory diseases of the joints and the spine, including osteoarthritis and low back pain caused by intervertebral disc degeneration, are major causes of disability in the elderly. In cell-based therapies for cartilage repair, transplanted ADSCs play a critical role in the efficacy of the therapy by interacting with local chondrocytes or cartilage explants in cartilage defects $[32,33]$. However, the involved mechanism in the paracrine influence of ADSCs on chondrocytes is still unclear. Studies show that the implantation of mixed ADSCs and chondrocytes into cartilage defects induces desirable in vivo healing outcomes. The BMP family members BMP-2, BMP-4, and BMP-5 are down-regulated, and VEGFB, HIF- $1 \alpha$, FGF-2, and PDGF are significantly decreased after co-culture. These results suggest that crosstalk between ADSCs and chondrocytes might have potential in cartilage repair and regeneration and could be also beneficial for cartilage tissue engineering [34].

\section{Cardiovascular and Myocardial Regeneration}

Molecular characterization of ADSCs not only has revealed their osteogenic, adipogenic and chondrogenic differentiation in vitro but also gives reason to suggest a myogenic potential of the ADSCs to further expand the mesodermal lineage. In recent years, cell therapies for cardiovascular and myocardial tissue regeneration have been an area of large interest. A variety of cell types have been shown to have a beneficial effect, especially for regeneration of the ischemic myocardium [35]. The paracrine factors can improve cardiac function by reducing the apoptosis of cardiomyocytes or by activating cardiac stem cells to increase cardiomyogenesis [36]. The therapeutic potential of ADSCs in the setting of chronic heart failure or acute myocardial infarction has been investigated by injecting them intracoronary. The ADSCs engrafted in the infarct region 4 weeks after cell transplantation and improved cardiac function, perfusion, and remodeling after acute myocardial infarction $[37,38]$.

In addition, ADSCs sparked the interest for application in cardiovascular tissue engineering and have been investigated as a source of interstitial cells to populate the heart valve constructs. It was shown that ADSCs can reproduce the major tissue structures that are required for proper valve functionality by producing matrix components, such as collagen and elastin, and by secreting matrix-enhancing or -degrading products $[39,40]$. Interestingly for the required anti-thrombogenicity of heart valve constructs, ADSCs are capable of differentiating into cells with phenotypic and functional features of endothelial cells $[39,40]$.

\section{Ectodermal Potential of ADSCs}

Recently, it has been shown that ADSCs can express specific markers of both the neuronal (NSE, nestin, MAP2, $\beta$-tubulin III) and the glial lineages (GFAP, NG2, p75 NGF receptor) when cultivated in the presence of the differentiation factors valproic acid, butylated hydroxyanisole, insulin, and hydrocortisone [41, 42]. 
The observed neuronal differentiation potential of ADSCs could be beneficial in the cell-therapeutic treatment of neuronal diseases, such as stroke [43] or Parkinson [44]. Stroke is a result of cerebral ischemia that triggers a cascade of both physiological and biochemical events. Currently no medication is effective for the treatment of stroke. However, stem cell therapies have the potential to resolve the effects of stroke [45]. More specifically, the ability of ADSCs to differentiate into neuron-like cells and other recent studies showing that human ADSCs significantly protect the endogenous neuron survival indicate that this cell source has a high clinical relevance for stroke therapy. ADSCs are known to ameliorate stroke symptoms by direct cell replacement, angiogenesis, enhanced immunosuppression, and an increase of the viability of endogenous neurons $[45,46]$. However, more research is required to improve the effectiveness of transplanted ADSCs as a treatment for stroke and other neurodegenerative diseases.

\section{Endodermal Potential of ADSCs}

According to the current literature, ADSCs can also differentiate into the endodermal lineage and therewith complete the tri-germ lineage potential. Some examples of the hepatic and pancreatic differentiation of ADSCs in human and rodents are described below.

\section{Hepatic Regeneration}

Although the molecular pathways behind the hepatic differentiation are still to be unraveled, ADSCs treated with HGF, oncostatin $\mathrm{M}$, and dimethylsulfoxide (DMSO) show the potential to develop a hepatocyte-like phenotype expressing albumin and $\alpha$-fetoprotein. Furthermore, these hepatocyte-like cells have the ability to take up low-density lipoprotein and to produce urea [47]. Additionally, in vivo studies showed that ADSCs were able to be differentiated into hepatocytes and capable to express albumin when transplanted into a CCl4-injured SCID mouse model [29, 48].

\section{Pancreatic Regeneration}

Beside the differentiation potential of ADSCs into the hepatic lineage, also the in vitro endodermal differentiation into the pancreatic lineage has been established. After induction with regenerating pancreatic extract or by co-culture with pancreatic adult stem cells in vitro, rat and human ADSCs not only express pancreatic markers, such as PDX1, CK19, IPF-1 and nestin, but also produce the pancreatic hormones insulin, somatostatin, and glucagon [49, 50]. According to these studies ADSCs have the potential to differentiate into pancreas cell lineages phenotypically in response to the regenerating pancreas extract or by co-culture with pancreatic adult stem cells.

\section{Cryopreservation of ADSCs}

For clinical practice and logistics, the preservation and banking of ADSCs is important concerning the future use of autologous cells based on the hope of the patients. For this purpose the cells have to be cryopreserved without losing their proliferation and differentiation capacity or their functionality. Meanwhile different protocols have been developed for clinic application. The main focus is on the reduction of the cytotoxic cryoprotectant DMSO [51] and a xenofree and chemically defined protocol [52]. Also the cryopreservation of adipose tissue for more than 2 years was successfully demonstrated [53].

\section{Methods to Advance the Therapeutic Effects of ADSCs}

The ability of ADSCs to secrete large amounts of specific growth factors, cytokines or other paracrine factors in their target environment can be utilized for therapeutic regenerative applications that rely on controlled drug release. For this concept, efforts to elucidate, augment, and harness stem cell paracrine mechanisms for tissue regeneration currently are undertaken. For example, in order to increase the amount of released trophic factors upon cell delivery in vivo, a number of different approaches have been examined that focus on genetic manipulation and in vitro preconditioning of ADSCs [54].

The potential of this concept has already been demonstrated for osteochondral regeneration. In an in vitro study, the osteogenic properties of ADSCs were enhanced by transducing these cells with an adenovirus to get an increased production of bone morphogenetic proteins such as BMP2 and BMP4 [55]. Similarly, ADSCs were transduced to secrete large amounts of VEGF to improve their angiogenic properties [56] in the therapeutic application in ischemic tissue. Amazingly the regenerative effect does not only rely on the soluble factors released by the ADSCs in vivo but also on the activation of the release of recipient's own secretomes [57].

\section{ADSCs as All-Rounder for Regenerative Medicine}

Due to their tri-germ lineage differentiation potential, ADSCs have good prerequisites for a broad range of therapeutic applications in regenerative medicine. Additionally, the immunosuppressive properties of ADSCs make them an attractive and clinically very relevant cell population for treatment of several immune-mediated diseases, including for instance graft-versus-host disease [58], Crohn's disease [59], and rheumatoid arthritis [60].

On the other hand, beside tissue restoration, vascularization is one of the most critical requirements for tissue healing. Interestingly, ADSCs appear to be key regulators of new blood vessel formation and have been demonstrated to differentiate easily to endothelial cells and to form quickly and simply vessel-like structures in Matrigel ${ }^{\circledR}$ substrates with assumed endothelial function [40]. Moreover, in different studies, regarding for instance cardiac infarct treatment, epithelial regeneration or neural tissue healing, vessel formation has been observed after injection of ADSCs alone or in the combination with other cell types $[61,62]$. 


\section{Current Gaps and Controversies: Tumorigenesis}

Notwithstanding all above mentioned marvelous and auspicious findings and their promising applications in regenerative medicine, it is relevant and critical to question whether these cells could promote any residual tumor cells to proliferate, differentiate, or metastasize or even induce de novo carcinogenesis. Therefore, the question whether these cells are safe for clinical application is heavily discussed in the current literature [63-65].

Amongst others, the research group of Wang et al. [66] described the suitability of ADSCs for the treatment of hepatocellular carcinoma. ADSCs inhibited hepatocellular carcinoma cell proliferation and division, and induced hepatocellular carcinoma cell death through the downregulation of Akt signaling, a signal pathway that promotes cell survival and growth in response to extracellular signals.

On the other hand, the prominent properties of ADSCs being pivotal for tissue regeneration have been shown to also create the perilous potential for tumor growth stimulation when the cells are used for cancer reconstruction [67]. The application of ADSCs, and more generally MSCs, results in tumor stimulation leading to engraftment of cells in the tumor mass. In case of breast cancer, the cancer cells stimulate de novo secretion of the chemokine CCL5 from MSCs, which then acts in a paracrine fashion on the cancer cells to enhance their motility, invasion, and metastasis [68].

Furthermore, interactions of human ADSCs with human squamous cell carcinoma cells were reported. The invasive behavior of squamous cell carcinoma cells was significantly increased in coculture with ADSCs, pointing towards a doubtlessly increased oncological risk [69].

Several reports have suggested ADSCs promote the proliferation of cancer cells [64], that means ADSCs may stimulate the growth of pre-existing tumors even if ADSCs per se do not form tumors. Consequently, the treatment with ADSCs in cancer diseases is not recommended as, in contrary, it could have dramatic side effects. These studies should not be ignored when considering clinical application of human ADSCs for regenerative therapies, even if no malignant behavior of MSCs has been reported in clinical studies so far [65].

\section{Regulatory and Commercialization Aspects}

The clinical use of cell-based therapies in regenerative medicine has to fulfill minimal requirements like any other medical treatment. In this regard, highest priority is given to the patient safety and the clinical efficiency. Remarkably, around the world stem cell therapy is being regulated by different guidelines and laws depending on the regulatory agencies in charge, e.g., the European Medicines Agency (EMA) in Europe, the Food and Drug Administration (FDA) in the USA, and other regional authorities. Consequently, some countries offer stem cell therapies that are not of fered elsewhere. Although this may positively impact the economics of individual countries because patients are willing to travel in hopes of healing, the lack of worldwide effective regulations concerning stem cell treatments is dangerous and could cause harm to the hopeless and therefore acquiescent patients.

In Europe, therapeutic products for clinical use that are based on gene therapy, somatic cell therapy, or tissue engineering are defined as advanced therapy medicinal products (ATMP). The European-Commission-(EC)-Regulation 1394/2007/EG for ATMP, and therefore cell- and tissue-based therapies, came into effect in December 2008. It covers specific guidelines on GMP and good clinical practice (GCP). Furthermore, it defines specific rules for labeling, packaging, and traceability as well as follow-up on efficacy, adverse reactions, and risk management obligation to the EMA and national authorities. This regulation is also ratified in Switzerland and defined in a national-specific way in the medicinal law (Heilmittelgesetz) and the transplantation law. The abidance of the law is inspected by Swiss Medic.

This hope of healing has drawn also commercial interest. TiGenix NV for instance, an advanced biopharmaceutical company, focused on developing and commercializing novel therapeutics from its proprietary platform of allogeneic, or donor-derived, expanded ADSCs in inflammatory and autoimmune diseases. Two products from this technology platform are currently in clinical development. Cx601 is in phase III for the treatment of complex perianal fistulas in Crohn's disease patients. Cx611 is in phase IIb for early rheumatoid arthritis and in phase Ib for severe sepsis. After intravenous administration of expanded allogeneic ADSCs in refractory rheumatoid arthritis, a trend for clinical efficacy was observed [70].

\section{Conclusions: Regenerative Potential of Adipose Tissue-Derived Stem Cells}

The promising therapeutic effects of ADSCs have been considered beneficial in regenerative therapies for numerous disease processes. ADSCs are considered to be ideal for application in regenerative therapies for several reasons. Namely, they can be harvested, handled, and expanded in a minimal invasive, easy, and effective manner and have a high potential for differentiation into mature cells along the mesodermal, ectodermal, and endodermal lineage [13]. Over the last years, important progress has been made regarding isolation, morphological characteristics, molecular biology, and the differentiation potential of in vitro stem cells, and it has become clear that ADSCs may mediate therapeutic effects. More precise, they do not only function as tissue-specific progenitor cells but also a multitude of mechanisms, such as paracrinemediated signaling of angiogenesis, inflammation, cell homing, cell survival, and similar processes, have emerged as primary mechanisms of action. These fundamental insights have helped to slowly close the gap between basic knowledge and clinical application and meanwhile the ADSCs have entered clinical trials throughout the world, showing to be safe and feasible in a variety of models.

Still, before ADSCs can be applied for routine clinical applications, many open questions related to ADSCs need to be solved. In 
order to completely understand the underlying mechanisms that regulate these cells, future experiments should, for example, focus on more precise markers for better and source-specific characterization of ADSCs. Also the genetic modification of the ex vivo expanded cells should not be neglected, and the regulators regarding differentiation, migration, and cell survival after in vivo transplantation have to be elucidated. Moreover, as the scientific understanding of the regenerative capacities and therewith number of possible applications of these cells increases, the potential perilous risks needs to be addressed, and the regulatory framework that governs their clinical use has to mature. Currently, specific regula- tory rules depend on the country were the therapy takes place. However, an effort toward the unification of policies across the globe is indispensable. In conclusion, advancements of science, regulatory policy, and commercial infrastructure are all important factors in the development and translation of this promising cell source.

\section{Disclosure Statement}

The authors declare that they have no conflict of interest.

\section{References}

1 Hyun I: The bioethics of stem cell research and therapy. J Clin Invest 2010;120:71-75.

2 Stoltz JF, de Isla N, Li YP, Bensoussan D, Zhang L, Huselstein C, Chen Y, Decot V, Magdalou J, Li N, Reppel L, He Y: Stem cells and regenerative medicine: myth or reality of the 21th century. Stem Cells Int 2015;2015: 734731.

3 Tavassoli M, Friedenstein A: Hemopoietic stromal microenvironment. Am J Hematol 1983;15:195-203.

4 Koobatian MT, Liang MS, Swartz DD, Andreadis ST: Differential effects of culture senescence and mechanical stimulation on the proliferation and leiomyogenic differentiation of MSC from different sources: implications for engineering vascular grafts. Tissue Eng Part A 2015;21:1364-1375.

5 Zuk PA, Zhu M, Ashjian P, De Ugarte DA, Huang JI, Mizuno H, Alfonso ZC, Fraser JK, Benhaim P, Hedrick $\mathrm{MH}$ : Human adipose tissue is a source of multipotent stem cells. Mol Biol Cell 2002;13:4279-4295.

6 Woo DH, Hwang HS, Shim JH: Comparison of adult stem cells derived from multiple stem cell niches. Biotechnol Lett 2016;38:751-759.

7 Zuk PA, Zhu M, Mizuno H, Huang J, Futrell JW, Katz AJ, Benhaim P, Lorenz HP, Hedrick MH: Multilineage cells from human adipose tissue: implications for cellbased therapies. Tissue Eng 2001;7:211-228.

8 Beane OS, Fonseca VC, Cooper LL, Koren G, Darling EM: Impact of aging on the regenerative properties of bone marrow-, muscle-, and adipose-derived mesenchymal stem/stromal cells. PLoS One 2014;9:e115963.

9 Xu H, Barnes GT, Yang Q, Tan G, Yang D, Chou CJ, Sole J, Nichols A, Ross JS, Tartaglia LA, Chen H: Chronic inflammation in fat plays a crucial role in the development of obesity-related insulin resistance. J Clin Invest 2003;112:1821-1830.

10 Digirolamo CM, Stokes D, Colter D, Phinney DG, Class R, Prockop DJ: Propagation and senescence of human marrow stromal cells in culture: a simple colony-forming assay identifies samples with the greatest potential to propagate and differentiate. Br J Haematol 1999; 107:275-281.

11 Sterodimas A, de Faria J, Nicaretta B, Pitanguy I: Tissue engineering with adipose-derived stem cells (ADSCs): current and future applications. J Plast Reconstr Aesthet Surg 2010;63:1886-1892.

12 Bieback K: Platelet lysate as replacement for fetal bovine serum in mesenchymal stromal cell cultures. Transfus Med Hemother 2013;40:326-335.
13 Bourin P, Bunnell BA, Casteilla L, Dominici M, Katz AJ, March KL, Redl H, Rubin JP, Yoshimura K, Gimble JM: Stromal cells from the adipose tissue-derived stromal vascular fraction and culture expanded adipose tissue-derived stromal/stem cells: a joint statement of the International Federation for Adipose Therapeutics and Science (IFATS) and the International Society for Cellular Therapy (ISCT). Cytotherapy 2013;15:641-648.

14 Oedayrajsingh-Varma MJ, van Ham SM, Knippenberg M, Helder MN, Klein-Nulend J, Schouten TE, Ritt MJ, van Milligen FJ: Adipose tissue-derived mesenchymal stem cell yield and growth characteristics are affected by the tissue-harvesting procedure. Cytotherapy 2006; 8:166-177.

15 Smith P, Adams WP Jr, Lipschitz AH, Chau B, Sorokin E, Rohrich RJ, Brown SA: Autologous human fat grafting: effect of harvesting and preparation techniques on adipocyte graft survival. Plast Reconstr Surg 2006;117: 1836-1844.

$16 \mathrm{Wu}$ W, Le AV, Mendez JJ, Chang J, Niklason LE, Steinbacher DM: Osteogenic performance of donormatched human adipose and bone marrow mesenchymal cells under dynamic culture. Tissue Eng Part A 2015;21:1621-1632.

17 Melief SM, Zwaginga JJ, Fibbe WE, Roelofs H: Adipose tissue-derived multipotent stromal cells have a higher immunomodulatory capacity than their bone marrowderived counterparts. Stem Cells Transl Med 2013;2: 455-463.

18 Strioga M, Viswanathan S, Darinskas A, Slaby O, Michalek J: Same or not the same? Comparison of adipose tissue-derived versus bone marrow-derived mesenchymal stem and stromal cells. Stem Cells Dev 2012; 21:2724-2752.

19 Steingen C, Brenig F, Baumgartner L, Schmidt J, Schmidt A, Bloch W: Characterization of key mechanisms in transmigration and invasion of mesenchymal stem cells. J Mol Cell Cardiol 2008;44:1072-1084.

20 Roh JD, Sawh-Martinez R, Brennan MP, Jay SM, Devine L, Rao DA, Yi T, Mirensky TL, Nalbandian A, Udelsman B, Hibino N, Shinoka T, Saltzman WM, Snyder E, Kyriakides TR, Pober JS, Breuer CK: Tissueengineered vascular grafts transform into mature blood vessels via an inflammation-mediated process of vascular remodeling. Proc Natl Acad Sci U S A 2010; 107:4669-4674.

21 Bertolini F, Lohsiriwat V, Petit JY, Kolonin MG: Adipose tissue cells, lipotransfer and cancer: A challenge for scientists, oncologists and surgeons. Biochim Biophys Acta 2012;1826:209-214.

22 http://clinicaltrials.gov, 2016.
23 Godoy Zanicotti D, Coates DE, Duncan WJ: In vivo bone regeneration on titanium devices using serumfree grown adipose-derived stem cells, in a sheep femur model. Clin Oral Implants Res 2016; doi: 10.1111/clr.12761

24 Lu W, Ji K, Kirkham J, Yan Y, Boccaccini AR, Kellett $\mathrm{M}$, Jin Y, Yang XB: Bone tissue engineering by using a combination of polymer/bioglass composites with human adipose-derived stem cells. Cell Tissue Res 2014;356:97-107.

25 Abudusaimi A, Aihemaitijiang Y, Wang YH, Cui L, Maimaitiming S, Abulikemu M: Adipose-derived stem cells enhance bone regeneration in vascular necrosis of the femoral head in the rabbit. J Int Med Res 2011;39: 1852-1860.

26 Lendeckel S, Jodicke A, Christophis P, Heidinger K, Wolff J, Fraser JK, Hedrick MH, Berthold L, Howaldt HP: Autologous stem cells (adipose) and fibrin glue used to treat widespread traumatic calvarial defects: case report. J Craniomaxillofac Surg 2004;32:370-373.

27 Missana MC, Laurent I, Barreau L, Balleyguier C: Autologous fat transfer in reconstructive breast surgery: Indications, technique and results. Eur J Surg Oncol 2007;33:685-690.

28 Weichman KE, Broer PN, Tanna N, Wilson SC, Allan A, Levine JP, Ahn C, Choi M, Karp NS, Allen R: The role of autologous fat grafting in secondary microsurgical breast reconstruction. Ann Plast Surg 2013;71: 24-30.

29 Suga H, Eto H, Shigeura T, Inoue K, Aoi N, Kato H, Nishimura S, Manabe I, Gonda K, Yoshimura K: IFATS collection: fibroblast growth factor-2-induced hepatocyte growth factor secretion by adipose-derived stromal cells inhibits postinjury fibrogenesis through a c-Jun $\mathrm{N}$-terminal kinase-dependent mechanism. Stem Cells 2009;27:238-249.

30 Steinstraesser L, Flak E, Witte B, Ring A, Tilkorn D, Hauser J, Langer S, Steinau HU, Al-Benna S: Pressure garment therapy alone and in combination with silicone for the prevention of hypertrophic scarring: randomized controlled trial with intraindividual comparison. Plast Reconstr Surg 2011;128:306e-313e.

31 Zhang Q, Liu LN, Yong Q, Deng JC, Cao WG: Intralesional injection of adipose-derived stem cells reduces hypertrophic scarring in a rabbit ear model. Stem Cell Res Ther 2015;6:145.

32 Li G, Fu N, Xie J, Fu Y, Deng S, Cun X, Wei X, Peng Q, Cai X, Lin Y: Poly(3-hydroxybutyrate-co-4-hydroxybutyrate) based electrospun 3D scaffolds for delivery of autogeneic chondrocytes and adipose-derived stem cells: evaluation of cartilage defects in rabbit. J Biomed Nanotechnol 2015;11:105-116. 
-33 Latief N, Raza FA, Bhatti FU, Tarar MN, Khan SN, Riazuddin S: Adipose stem cells differentiated chondrocytes regenerate damaged cartilage in rat model of osteoarthritis. Cell Biol Int 2016;40:579-588.

34 Zhong J, Guo B, Xie J, Deng S, Fu N, Lin S, Li G, Lin Y, Cai X: Crosstalk between adipose-derived stem cells and chondrocytes: when growth factors matter. Bone Res 2016;4:15036.

35 Schaun MI, Eibel B, Kristocheck M, Sausen G, Machado L, Koche A, Markoski MM: Cell therapy in ischemic heart disease: interventions that modulate cardiac regeneration. Stem Cells Int 2016;2016:2171035.

36 Gnecchi M, He H, Liang OD, Melo LG, Morello F, Mu H, Noiseux N, Zhang L, Pratt RE, Ingwall JS, Dzau VJ: Paracrine action accounts for marked protection of ischemic heart by Akt-modified mesenchymal stem cells. Nat Med 2005;11:367-368.

37 Valina C, Pinkernell K, Song YH, Bai X, Sadat S, Campeau RJ, Le Jemtel TH, Alt E: Intracoronary administration of autologous adipose tissue-derived stem cells improves left ventricular function, perfusion, and remodelling after acute myocardial infarction. Eur Heart J 2007;28:2667-2677.

38 Nagata H, Ii M, Kohbayashi E, Hoshiga M, Hanafusa T, Asahi M: Cardiac adipose-derived stem cells exhibit high differentiation potential to cardiovascular cells in C57BL/6 mice. Stem Cells Transl Med 2016;5:141-151.

-39 Frese L, Sanders B, Beer GM, Weber B, Driessen-Mol A, Baaijens FPT, Hoerstrup SP: Adipose derived tissue engineered heart valve. J Tissue Sci Eng 2015;6:156.

40 Colazzo F, Chester AH, Taylor PM, Yacoub MH: Induction of mesenchymal to endothelial transformation of adipose-derived stem cells. J Heart Valve Dis 2010; 19:736-744

41 Madhu V, Dighe AS, Cui Q, Deal DN: Dual inhibition of activin/nodal/TGF-beta and BMP signaling pathways by SB431542 and dorsomorphin induces neuronal differentiation of human adipose derived stem cells. Stem Cells Int 2016;2016:1035374.

42 Radtke C, Schmitz B, Spies M, Kocsis JD, Vogt PM: Peripheral glial cell differentiation from neurospheres derived from adipose mesenchymal stem cells. Int $\mathrm{J}$ Dev Neurosci 2009;27:817-823.

43 Gutierrez-Fernandez M, Otero-Ortega L, RamosCejudo J, Rodriguez-Frutos B, Fuentes B, Diez-Tejedor E: Adipose tissue-derived mesenchymal stem cells as a strategy to improve recovery after stroke. Expert Opin Biol Ther 2015; 15:873-881.

44 Schwerk A, Altschuler J, Roch M, Gossen M, Winter C, Berg J, Kurtz A, Akyuz L, Steiner B: Adipose-derived human mesenchymal stem cells induce long-term neurogenic and anti-inflammatory effects and improve cognitive but not motor performance in a rat model of Parkinson's disease. Regen Med 2015;10:431-446.

45 Hao L, Zou Z, Tian H, Zhang Y, Zhou H, Liu L: Stem cell-based therapies for ischemic stroke. Biomed Res Int 2014;2014:468748.

46 Zhou F, Gao S, Wang L, Sun C, Chen L, Yuan P, Zhao H, Yi Y, Qin Y, Dong Z, Cao L, Ren H, Zhu L, Li Q, Lu B, Liang A, Xu GT, Zhu H, Gao Z, Ma J, Xu J, Chen X: Human adipose-derived stem cells partially rescue the stroke syndromes by promoting spatial learning and memory in mouse middle cerebral artery occlusion model. Stem Cell Res Ther 2015;6:92.
47 Xu D, Nishimura T, Zheng M, Wu M, Su H, Sato N, Lee G, Michie S, Glenn J, Peltz G: Enabling autologous human liver regeneration with differentiated adipocyte stem cells. Cell Transplant 2014;23:1573-1584.

48 Seo MJ, Suh SY, Bae YC, Jung JS: Differentiation of human adipose stromal cells into hepatic lineage in vitro and in vivo. Biochem Biophys Res Commun 2005;328:258-264.

49 Lee J, Han DJ, Kim SC: In vitro differentiation of human adipose tissue-derived stem cells into cells with pancreatic phenotype by regenerating pancreas extract. Biochem Biophys Res Commun 2008;375:547-551.

50 Hefei W, Yu R, Haiqing W, Xiao W, Jingyuan W, Dongjun L: Morphological characteristics and identification of islet-like cells derived from rat adipose-derived stem cells cocultured with pancreas adult stem cells. Cell Biol Int 2015;39:253-263.

51 De Rosa A, De Francesco F, Tirino V, Ferraro GA, Desiderio V, Paino F, Pirozzi G, D’Andrea F, Papaccio G: A new method for cryopreserving adipose-derived stem cells: an attractive and suitable large-scale and long-term cell banking technology. Tissue Eng Part C Methods 2009;15:659-667.

52 Schulz JC, Germann A, Kemp-Kamke B, Mazzotta A, von Briesen $\mathrm{H}$, Zimmermann $\mathrm{H}$ : Towards a xeno-free and fully chemically defined cryopreservation medium for maintaining viability, recovery, and antigen-specific functionality of PBMC during long-term storage. J Immunol Methods 2012;382:24-31.

53 Devitt SM, Carter CM, Dierov R, Weiss S, Gersch RP, Percec I: Successful isolation of viable adipose-derived stem cells from human adipose tissue subject to longterm cryopreservation: positive implications for adult stem cell-based therapeutics in patients of advanced age. Stem Cells Int 2015;2015:146421.

54 Phillips MI, Tang YL: Genetic modification of stem cells for transplantation. Adv Drug Deliv Rev 2008;60: 160-172.

55 Lin L, Fu X, Zhang X, Chen LX, Zhang JY, Yu CL, Ma KT, Zhou CY: Rat adipose-derived stromal cells expressing BMP4 induce ectopic bone formation in vitro and in vivo. Acta Pharmacol Sin 2006;27:1608-1615.

56 Shevchenko EK, Makarevich PI, Tsokolaeva ZI, Boldyreva MA, Sysoeva VY, Tkachuk VA, Parfyonova YV: Transplantation of modified human adipose derived stromal cells expressing VEGF165 results in more efficient angiogenic response in ischemic skeletal muscle. J Transl Med 2013;11:138.

57 Yiou R, Mahrouf-Yorgov M, Trebeau C, Zanaty M, Lecointe C, Souktani R, Zadigue P, Figeac F, Rodriguez AM: Delivery of human mesenchymal adipose-derived stem cells restores multiple urological dysfunctions in a rat model mimicking radical prostatectomy damages through tissue-specific paracrine mechanisms. Stem Cells 2016;34:392-404

58 Fang B, Song Y, Liao L, Zhang Y, Zhao RC: Favorable response to human adipose tissue-derived mesenchymal stem cells in steroid-refractory acute graft-versushost disease. Transplant Proc 2007;39:3358-3362.

59 Lee WY, Park KJ, Cho YB, Yoon SN, Song KH, Kim do S, Jung SH, Kim M, Yoo HW, Kim I, Ha H, Yu CS: Autologous adipose tissue-derived stem cells treatment demonstrated favorable and sustainable therapeutic effect for Crohn's fistula. Stem Cells 2013;31:2575-2581.
60 Garimella MG, Kour S, Piprode V, Mittal M, Kumar A, Rani L, Pote ST, Mishra GC, Chattopadhyay N, Wani MR: Adipose-derived mesenchymal stem cells prevent systemic bone loss in collagen-induced arthritis. J Immunol 2015;195:5136-5148.

61 Rohringer S, Hofbauer P, Schneider KH, Husa AM, Feichtinger G, Peterbauer-Scherb A, Redl H, Holnthoner W: Mechanisms of vasculogenesis in 3D fibrin matrices mediated by the interaction of adiposederived stem cells and endothelial cells. Angiogenesis 2014;17:921-933.

62 Merfeld-Clauss S, Lupov IP, Lu H, March KL, Traktuev DO: Adipose stromal cell contact with endothelial cells results in loss of complementary vasculogenic activity mediated by induction of activin A. Stem Cells 2015;33:3039-3051.

63 Jeong JO, Han JW, Kim JM, Cho HJ, Park C, Lee N, Kim DW, Yoon YS: Malignant tumor formation after transplantation of short-term cultured bone marrow mesenchymal stem cells in experimental myocardial infarction and diabetic neuropathy. Circ Res 2011;108: 1340-1347.

64 Ji SQ, Cao J, Zhang QY, Li YY, Yan YQ, Yu FX: Adipose tissue-derived stem cells promote pancreatic cancer cell proliferation and invasion. Braz J Med Biol Res 2013;46:758-764.

65 Centeno CJ, Schultz JR, Cheever M, Freeman M, Faulkner S, Robinson B, Hanson R: Safety and complications reporting update on the re-implantation of culture-expanded mesenchymal stem cells using autologous platelet lysate technique. Curr Stem Cell Res Ther 2011;6:368-378

66 Zhao W, Ren G, Zhang L, Zhang Z, Liu J, Kuang P, Yin $Z$, Wang X: Efficacy of mesenchymal stem cells derived from human adipose tissue in inhibition of hepatocellular carcinoma cells in vitro. Cancer Biother Radiopharm 2012;27:606-613.

67 Donnenberg VS, Zimmerlin L, Rubin JP, Donnenberg $\mathrm{AD}$ : Regenerative therapy after cancer: what are the risks? Tissue Eng Part B Rev 2010;16:567-575.

68 Karnoub AE, Dash AB, Vo AP, Sullivan A, Brooks MW, Bell GW, Richardson AL, Polyak K, Tubo R, Weinberg RA: Mesenchymal stem cells within tumour stroma promote breast cancer metastasis. Nature 2007; 449:557-563.

69 Koellensperger E, Gramley F, Preisner F, Leimer U, Germann G, Dexheimer V: Alterations of gene expression and protein synthesis in co-cultured adipose tissue-derived stem cells and squamous cell-carcinoma cells: consequences for clinical applications. Stem Cell Res Ther 2014;5:65.

70 Alvaro-Gracia JM, Jover JA, Garcia-Vicuna R, Carreno L, Alonso A, Marsal S, Blanco F, Martinez-Taboada VM, Taylor P, Martin-Martin C, DelaRosa O, Tagarro I, Diaz-Gonzalez F: Intravenous administration of expanded allogeneic adipose-derived mesenchymal stem cells in refractory rheumatoid arthritis (Cx611): results of a multicentre, dose escalation, randomised, singleblind, placebo-controlled phase Ib/IIa clinical trial. Ann Rheum Dis 2016; doi: 10.1136/annrheumdis-2015208918. 